\title{
Store-Independent Calcium Entry and Related Signaling Pathways in Breast Cancer
}

\author{
Mohamed Chamlali, Lise Rodat-Despoix (D) and Halima Ouadid-Ahidouch *
}

Laboratory of Cellular and Molecular Physiology, UR-UPJV 4667, University of Picardie Jules Verne, 80000 Amiens, France; mohamed.chamlali@etud.u-picardie.fr (M.C.); lise.despoix@u-picardie.fr (L.R.-D.)

* Correspondence: halima.ahidouch-ouadid@u-picardie.fr

check for

updates

Citation: Chamlali, M.;

Rodat-Despoix, L.; Ouadid-Ahidouch, H. Store-Independent Calcium Entry and Related Signaling Pathways in Breast Cancer. Genes 2021, 12, 994. https://doi.org/10.3390/ genes12070994

Academic Editor: Iman Azimi and Irmgard Irminger-Finger

Received: 20 April 2021

Accepted: 25 June 2021

Published: 29 June 2021

Publisher's Note: MDPI stays neutral with regard to jurisdictional claims in published maps and institutional affiliations.

Copyright: (c) 2021 by the authors. Licensee MDPI, Basel, Switzerland. This article is an open access article distributed under the terms and conditions of the Creative Commons Attribution (CC BY) license (https:// creativecommons.org/licenses/by/ $4.0 /)$.
Abstract: Known as a key effector in breast cancer (BC) progression, calcium $\left(\mathrm{Ca}^{2+}\right)$ is tightly regulated to maintain the desired concentration to fine-tune cell functions. $\mathrm{Ca}^{2+}$ channels are the main actors among $\mathrm{Ca}^{2+}$ transporters that control the intracellular $\mathrm{Ca}^{2+}$ concentration in cells. It is well known that the basal $\mathrm{Ca}^{2+}$ concentration is regulated by both store-dependent and independent $\mathrm{Ca}^{2+}$ channels in $\mathrm{BC}$ development and progression. However, most of the literature has reported the role of store-dependent $\mathrm{Ca}^{2+}$ entry, and only a few studies are focusing on store-independent $\mathrm{Ca}^{2+}$ entry (SICE). In this review, we aim to summarize all findings on SICE in the BC progression field.

Keywords: calcium channels; basal calcium entry; Orai- $\mathrm{K}^{+}$channel complex; transient receptor potential channels; voltage-gated calcium channels; breast cancer

\section{Introduction}

Cancers are a major public health problem due to their incidence and, more particularly, their mortality. Among all cancers, breast cancer (BC) is one of the most diagnosed in the world. Despite significant discoveries in treatment, some BC are currently incurable. Thereby, we still need to identify targets to treat BC. In recent years, a research field has developed around the role of ion channels and their implication in tumor progression [1] The involvement of ion transporters in tumor development could thus classify cancers as onco-channelopathies [2]. Furthermore, several studies reported the involvement of calcium $\left(\mathrm{Ca}^{2+}\right)$ channels in almost all hallmarks of cancer [3]. Research on $\mathrm{BC}$ has shown the involvement of a certain number of proteins related to its development and progression. It has also been found that $\mathrm{Ca}^{2+}$-regulating proteins are key effectors in $\mathrm{BC}$. Indeed, $\mathrm{Ca}^{2+}$ is recognized as a universal intracellular second messenger involved in a plethora of physiological as well as physiopathological processes, such as cell proliferation, migration, invasion, apoptosis, and chemoresistance in a cancer situation [4,5]. Many studies have already clarified the role of $\mathrm{Ca}^{2+}$ signaling in cancer and especially $\mathrm{BC}$, suggesting its importance in the altering processes that shape cancer cells [6]. However, calcium transport and its regulation remain to be completely understood.

Several pathways, with different modes of action, permit a $\mathrm{Ca}^{2+}$ influx. The most known is the store-operated $\mathrm{Ca}^{2+}$ entry (SOCE) pathway which is regulated by the activation of the $\mathrm{Ca}^{2+}$ release-activated channels encoded by Orai channels via stromal interaction molecule (STIM) proteins [7]. It is well known in the literature that these channels play critical roles in carcinogenesis, including BC [8]. However, recent studies have reported the role of store-independent $\mathrm{Ca}^{2+}$ entry (SICE) in regulating $\mathrm{BC}$ processes and several hallmarks of BC. Indeed, SICE is known to be induced either by arachidonic acid (AA) and/or the AA metabolite leukotriene C4 (LTC4) pathways and regulated by both Orai1 and Orai3 channels [9], or by the functional coupling between Orai1 and secretory pathway $\mathrm{Ca}^{2+}$-ATPase (SPCA2) [10]. In addition to these two major pathways, SICE can also be mediated by voltage-gated $\mathrm{Ca}^{2+}$ channels (VGCC), mechanosensitive $\mathrm{Ca}^{2+}$ channels, ligand-activated $\mathrm{Ca}^{2+}$ channels, as well as constitutively activated $\mathrm{Ca}^{2+}$ channels [11-13]. 
Several reviews have focused on the description and role of SOCE through the stromal interaction molecule (STIM) protein activation $[8,14]$. However, studies on SICE remain elusive. In this review, we aimed to summarize the different studies which have shown the role of SICE in the regulation of $\mathrm{BC}$ processes.

\section{Orai Channels}

Orai channels play distinct roles in different BC subtypes [15]. Two isoforms (Orai1 and Orai3) in particular have been found overexpressed in BC. Regarding Orai3, it was found overexpressed in $76.9 \%$ of 13 tested $\mathrm{BC}$ samples when compared to non-tumoral breast ones [16]. In addition, a positive correlation between Orai3 and the c-Myc proto-oncogene transcriptional expression in BC tissues has also been reported [17]. By analyzing Orai3 in clinical BC samples through the analysis of a public dataset, Hasna et al. proposed Orai3 as a predictive marker in the resistance to chemotherapeutic drugs [18]. Subsequently, a study conducted by Azimi et al. reported a sensitivity of Orai3 to hypoxia [19]. They observed an increase in Orai3 expression in response to hypoxia in both basal and luminal types of BC cells, and identified hypoxia and hypoxia-inducible factor $1 \alpha$ (HIF $1 \alpha)$ as critical regulators of Orai3 expression in these types of cell lines [19]. Finally, Orai3 transcriptional expression is regulated via the expression of micro-ribonucleic acid (miRNA). Indeed, it has been shown that miR34A and miR18A/B inhibit and activate Orai3 expression, respectively [20]. On the other hand, Orai1 was found expressed in the mammary gland and its expression increased during lactation assuming the trans-epithelial $\mathrm{Ca}^{2+}$ transport [21]. Orai1 was also found up-regulated in BC cell lines and is particularly highly expressed in basal subtype cells where it regulates migration $[19,21,22]$.

Interestingly, an association between Orai channels and transient receptor potential canonical 6 (TRPC6) channels has been reported. Thus, both Orai1 and Orai3 plasma membrane localization is allowed by TRPC6 in BC. Indeed, TRPC6 calcium activity permits these Orai isoforms to be translocated to the plasma membrane and thus participates in a novel way to modulate the $\mathrm{Ca}^{2+}$ influx in $\mathrm{BC}$ [23].

Several studies have shown an activation mode of Orai1 and Orai3 depending on the estrogenic status and/or the histological origin [21,22,24]. Orai3 contributes to the SOCE in luminal cells expressing estrogen receptors $\left(\mathrm{ER}^{+}\right)$such as MCF-7 and T47D cell lines, but not in the estrogen-negative (ER ${ }^{-}$) basal cells such as MDA-MB-231 [24], while Orai1 mediates SOCE in basal-like BC cell lines [22,24]. However, Orai1 still regulates SOCE in $\mathrm{ER}^{+} \mathrm{BC}$ cell lines such as MCF-7 [21].

Orai1 is the most studied channel among the store-operated channels (SOC). Some studies have shown a modulation of the $\mathrm{Ca}^{2+}$ entry through Orai1, which does not depend on the $\mathrm{Ca}^{2+}$ store depletion. Indeed, in 2010, Feng et al. demonstrated another mode of activation of the Orai1 channels [10]. In luminal ER ${ }^{+}$cells, Orai1, which is activated independently from STIM1, regulates basal $\mathrm{Ca}^{2+}$ entry and $\mathrm{Ca}^{2+}$ homeostasis. This mechanism involves the SPCA2 pumps initially located in the Golgi apparatus [10]. It has been demonstrated by co-immunoprecipitation and pull-down techniques that SPCA2 via its amino-terminus (N-ter) physically interacts with Orail at the level of the plasma membrane, which results in the activation of Orai1 by SPCA2 carboxyl-terminus (C-ter) and thus in an increase in the basal $\mathrm{Ca}^{2+}$ concentration [10]. Interestingly, the SCPA2/Orai1 coupling has also been shown in a cell model of lactation. Indeed, SPCA2 and Orai1 were found co-localized in mouse lactating glands and participate in a SICE to support lactation [25]. Therefore, it seems that BC cells redirect this SPCA2-dependent Orai1 activation to acquire cancer capacities. SICE induced by the Orai1/SPCA2 coupling has also been shown in the MCF-7 cell line, where it regulates cell proliferation [10]. Moreover, our team reported that SPCA2 also constitutes a complex with $\mathrm{Kv} 10.1$ potassium $\left(\mathrm{K}^{+}\right)$channels in $\mathrm{ER}^{+}$cell lines and allows its trafficking from the Golgi to the plasma membrane [26]. Both SPCA2 N-ter and C-ter are involved in this trafficking [27]. Indeed, in MCF-7 cells, SPCA2 regulates the localization and the activity of both Kv10.1 and Orai1 channels, mediating a SICE able to 
sustain channel membrane localization and Erk1/2 phosphorylation, and to promote cell survival in a collagen environment [26,28].

As seen above, when a store-independent activation of Orai1 occurs, other proteins are involved to form a functional or physical complex with Orai1. It is the case in potassium channels. $\mathrm{K}^{+}$channel activity permits $\mathrm{K}^{+}$ion efflux that induces a membrane potential hyperpolarization, therefore, increasing the driving force for $\mathrm{Ca}^{2+}$ that favors $\mathrm{Ca}^{2+}$ entry in the cell [29]. Both the voltage-gated $\mathrm{Kv10.1}$ and the small-conductance $\mathrm{Ca}^{2+}$-activated potassium channel (SK3) were found to work in partnership with Orai1. Indeed, these $\mathrm{K}^{+}$ channels, by regulating the membrane potential, regulate $\mathrm{Ca}^{2+}$ entry in basal-like $\mathrm{BC}$ cells.

For both of these channels, it has been found that Orai1 was the main actor in the constitutive $\mathrm{Ca}^{2+}$ entry in BC. In fact, both Kv10.1 and SK3 functionally regulate the $\mathrm{Ca}^{2+}$ entry through Orai1 leading the cell migration regulation. Indeed, Kv10.1 was observed expressed alongside Orai1 in invasive breast tumors and lymph node metastasis, and regulates cell migration through an Orai1-dependent constitutive $\mathrm{Ca}^{2+}$ entry [30]. On the other hand, it has been shown that SK3 knockdown inhibits BC bone metastasis [31]. This process is explained by the fact that, in the basal MDA-MB-435S cell line, Orai1 is recruited with SK3 to the lipid rafts, and following the SK3-dependent hyperpolarization, Orai1 is activated in a store-independent manner. Moreover, the same team showed an involvement of the SigmaR1 protein in the activity and localization of SK3 in lipid rafts [32]. The SICE through Orai1 activates the calpain leading to cell migration in the MDA-MB-435S cell line $[31,32]$.

\section{TRP Channels}

The transient receptor potential (TRP) channels family is expressed and functional in most of the non-excitable cells in the human organism. They are known to be activated by various stimuli, such as growth factors, temperature, ligand, or mechanical stimuli, and are known to be abnormally expressed in cancers and especially BC. Many TRP channels have been identified as being up-regulated in $\mathrm{BC}$ and can be correlated with clinical parameters in BC. This is the case, for example, for TRP canonical (TRPC) channels (TRPC1, TRPC3, and TRPC6), TRP melastatin (TRPM) channels (TRPM6, TRPM7, and TRPM8), and TRP vanilloid (TRPV) channels (TRPV1, TRPV2, TRPV3, TRPV4, TRPV5, and TRPV6) [33-38]. In addition, it has been shown that TRPC 6 is upregulated in BC cell lines and patient tissue compared to normal breast cell lines and healthy tissue, respectively [39]. However, TRPC6 expression is not correlated with tumor grades, estrogen receptor expression, or lymph node-positive tumors. Furthermore, the overexpression of TRPC1 has been discovered to be correlated with small tumors low proliferating (Grade 1), whereas TRPV4 is correlated with tumor grade, tumor size, and patient overall survival [40]. Moreover, given the estrogen-dependent trait observed in some BC, the TRPM8 channel has been shown to have its expression regulated by estrogen. Indeed, the application of estrogen on the MCF-7 cell line increases the expression of TRPM8 [33]. Both the role and expression of TRPM7 have been shown to depend on estrogen and/or aggressiveness status. Indeed, in $\mathrm{ER}^{-}$tumors (not expressing the estrogen receptor and known to be the most aggressive), TRPM7 appears to be overexpressed in the most invasive areas [41], correlated to cancer metastasis and invasive BC [42], and regulates migration [41]. While in ER tumors, TRPM7 is overexpressed in the non-invasive areas, but at a lower level than in the invasive areas, and regulates cell proliferation [37].

In addition, it has also been shown that the TRPC1 channel expression is regulated via activation of the calcium-sensing receptor ( $\mathrm{CaR})$ [43]. Indeed, the activation of $\mathrm{CaR}$ by extracellular $\mathrm{Ca}^{2+}$ (up to $10 \mathrm{mM}$ ) increases TRPC1 expression, via the phospholipase $\mathrm{C}$ (PLC) and Erk1/2 pathway in MCF-7 cells [43-45]. Furthermore, TRPC1 is required for Erk1/2 phosphorylation and $\mathrm{Ca}^{2+}$ entry, and also for the proliferative effect induced by the activation of $\mathrm{CaR}$. Moreover, the involvement of TRPC1 in the CaR-induced proliferation has been suggested [43]. 
Interestingly, TRPC1 expression is upregulated in hypoxia compared to normoxia conditions through HIF1 $\alpha$ expression due to the presence of HIF1 $\alpha$ and HIF1 $\beta$ binding domains in the TRPC1 gene promoter [46]. Silencing of HIF1 $\alpha$, but not HIF1 $\beta$ nor HIF2 $\alpha$, reduced TRPC1 expression. In basal BC cells under hypoxia, TRPC1 contributes to a basal $\mathrm{Ca}^{2+}$ entry and an increase of intracellular $\mathrm{Ca}^{2+}$ concentration in a constitutive manner. Indeed, TRPC 1 silencing reduces the constitutive $\mathrm{Ca}^{2+}$ entry in cells grown under a hypoxic environment [46]. Moreover, the same study showed that TRPC1 promotes the epithelialto-mesenchymal transition (EMT) in hypoxic conditions with an upregulation of the Snail1 mesenchymal marker via HIF1 $\alpha$ signaling and downregulation of the epithelial maker Claudin-4 [46]. In addition, TRPC1 positively regulates the expression of the autophagy maker LC3BII through activation of the epidermal growth factor receptor (EGFR) as well as signal transducers and activators of transcription 3 (STAT3) phosphorylation during hypoxia [46].

In BC, Lee et al. have shown that TRPV4 calcium activity is required in cell migration via activation of the Akt signaling pathway as well as a downregulation of E-cadherin protein expression. In this study, they showed that activation of the upregulated TRPV4 by $4-\alpha$-phorbol-12,13-didecanoate (4 $\alpha$-PDD) triggers a $\mathrm{Ca}^{2+}$ influx responsible for the $\mathrm{Akt}$ signaling pathway and a sustainable phosphorylation of FAK which could be via the Akt signaling pathway. Moreover, Akt activation is responsible for a downregulation of $\beta$-catenin and E-cadherin [40]. Moreover, the activation of TRPV4 induces an EMT in MDA-MB-468 cells by increasing the expression of EMT markers, such as Vimentin, AXL, Serpin1, Twist, Snail, and CD44/CD24 ratio. In contrast, TRPV4-silenced cells presented a reduced single-cell motility but no change in the EMT markers' expression [47].

The melastatin family of TRP channels is also a well-known regulator of carcinogenesis processes. For example, our team showed that TRPM7 is a key regulator in BC progression. It participates in cell proliferation as well as cell migration and invasion [37,41,42]. First, it has been found that TRPM7 silencing decreases the constitutive $\mathrm{Ca}^{2+}$ entry and hence the cell viability [37]. Guilbert et al. established that TRPM7 basal activity regulates $\mathrm{ER}^{+}$ $\mathrm{BC}$ cell line progression. In addition, they demonstrated that TRPM7 silencing decreased both $\mathrm{Ca}^{2+}$ entry and MCF-7 cell line proliferation [37]. However, it has been shown that TRPM7 regulates MDA-MB-231 cell line migration via its catalytic kinase domain, and not through its channel activity, by regulating the myosin II-based cytoskeletal tension and thereby SRY-Box transcription factor 4 (SOX4) [41,48,49]. Furthermore, research work on the MDA-MB-435S cell line showed that TRPM7 knockdown decreases both cell migration and invasion following a decrease in the MAPK protein phosphorylation [42]. However, this study does not show a direct channel activation of TRPM7, particularly when TRPM7 presents a kinase-type catalytic domain [42].

Another TRPM family member, the $\mathrm{Ca}^{2+}$-permeable TRPM8 channel, was found as a regulator of $\mathrm{BC}$ processes. This channel was shown to be activated in $\mathrm{BC}$ cells and associated with an elevation of cytosolic $\mathrm{Ca}^{2+}$ concentration following the application of icilin (TRPM8 agonist) [33]. However, the estrogen status does not seem to be involved in the TRPM8 activation state since $17 \beta$-estradiol increased TRPM8 mRNA expression but failed to affect the $\mathrm{Ca}^{2+}$ entry [33]. Moreover, it has been shown that TRPM8, following menthol or icilin activation, regulates BC cell proliferation and migration via activation of AMP-activated protein kinase-Unc-51 like autophagy activating the kinase 1 (AMPKULK1) signaling pathway, suggesting that TRPM8, by regulating the autophagy, leads the proliferative and migratory processes [50].

\section{Voltage-Gated Calcium Channels}

A number of studies have focused on the role of VGCC, which could be activated under normal cell culture conditions. Indeed, the resting membrane potential, measured by whole-cell patch-clamp technique, varies from -40 to $-20 \mathrm{mV}$ in BC cell lines [51-53]. The opening of VGCC at rest allows, therefore, a basal $\mathrm{Ca}^{2+}$ entry. Some VGCC see their expression and activity being altered in BC. This is the case in T-type $\mathrm{Ca}^{2+}$ channels, such 
as Cav3.1, Cav3.2, which are overexpressed in BC tissue [54,55]. Indeed, through an experimental and informatic study using microarray analysis, it has been found that certain L-type channels, such as Cav1.2 and Cav1.3, seem to be overexpressed in different types of cancer, including $\mathrm{BC}$, and participate in inward $\mathrm{Ca}^{2+}$ entry following melatonin and $5 \alpha$-dihydrotestosterone perfusion [56-58].

L-type VGCC were found to be active at a basal level and regulated by the L-type voltage-gated calcium channel $\gamma 4$ subunit (CACNG4) [59]. CACNG4 modulates L-type VGCC basal activation, and thereby the downstream processes. This subunit has been found to be involved in BC cell proliferation, motility, and adhesion. Its silencing reduced these cellular processes and its overexpression increased the metastasis to the lungs in vivo. Treatment with L-type channels antagonists Verapamil and Amlodipine decreased the MCF-7 and MDA-MB-231 cell proliferation. It has also been shown that CACNG4 silencing led to an increase in $\mathrm{Ca}^{2+}$ entry. However, the application of L-type channel antagonists decreased $\mathrm{Ca}^{2+}$ entry. These results suggested that CACNG4 subunit regulates the channel in an active state resulting in the higher intracellular $\mathrm{Ca}^{2+}$ concentration leading in fine to the inhibition of processes such as cell proliferation, motility, and adhesion [59]. Moreover, L-type VGCC are involved in BC cell invasion [60]. The activation of the L-type $\mathrm{Ca}^{2+}$ channel with a specific agonist BAY K8644 leads to an increase in the intracellular $\mathrm{Ca}^{2+}$ concentration responsible for filopodia stability. Indeed, treated cells with L-type channels pharmacological blockers, such as amlodipine besylate, felopidine, manidipine dichloride, and cilnipidine, lose their stable filopodia. Furthermore, it has been shown in the same study that integrin activation promotes filopodia formation through the proto-oncogene tyrosine-protein kinase Src signaling pathway, calpain activity, as well as a $\mathrm{Ca}^{2+}$ entry at the filopodia level. In addition, the L-type $\mathrm{Ca}^{2+}$ channel seems to be colocalized with myosin $\mathrm{X}$ (MYO10) within filopodia [60].

T-type $\mathrm{Ca}^{2+}$ channels, active at membrane potential from $-50 \mathrm{mV}$ and above [61], have been reported to regulate BC cell proliferation. Selective knockdown or pharmacological targeting to inhibit T-type $\mathrm{Ca}^{2+}$ channels reduced MCF-7 cell proliferation without altering cell viability [62]. A similar study was conducted and showed that treatment with mibefradil and pimozid ( $\mathrm{Ca}^{2+}$ channel antagonists) inhibited T-type $\mathrm{Ca}^{2+}$ currents and reduced cell proliferation. However, due to the poor selectivity of the pharmacological blockers used, it has been concluded that T-type $\mathrm{Ca}^{2+}$ channels are involved in the cell proliferation alongside other VGCC, such as L-type $\mathrm{Ca}^{2+}$ channels [61].

\section{Conclusions}

To summarize, $\mathrm{Ca}^{2+}$ channels are a protein family activated by a plethora of stimuli from store-dependent activation to the basal-activated state in BC. Based on studies demonstrated in this review, it seems that $\mathrm{Ca}^{2+}$ signaling is far from being fully understood in $\mathrm{BC}$. As we schematized, the SICE constitutes a key effector in a multitude of $\mathrm{BC}$ cell processes, even though it is not the major actor in the $\mathrm{Ca}^{2+}$ flow as SOCE (see Figure 1). Nevertheless, further studies on $\mathrm{Ca}^{2+}$-regulated cell processes in $\mathrm{BC}$ should bring answers regarding the relationship and/or the complementarity between the role of SOCE and SICE in the regulation of $\mathrm{BC}$ progression via $\mathrm{Ca}^{2+}$ signaling. 


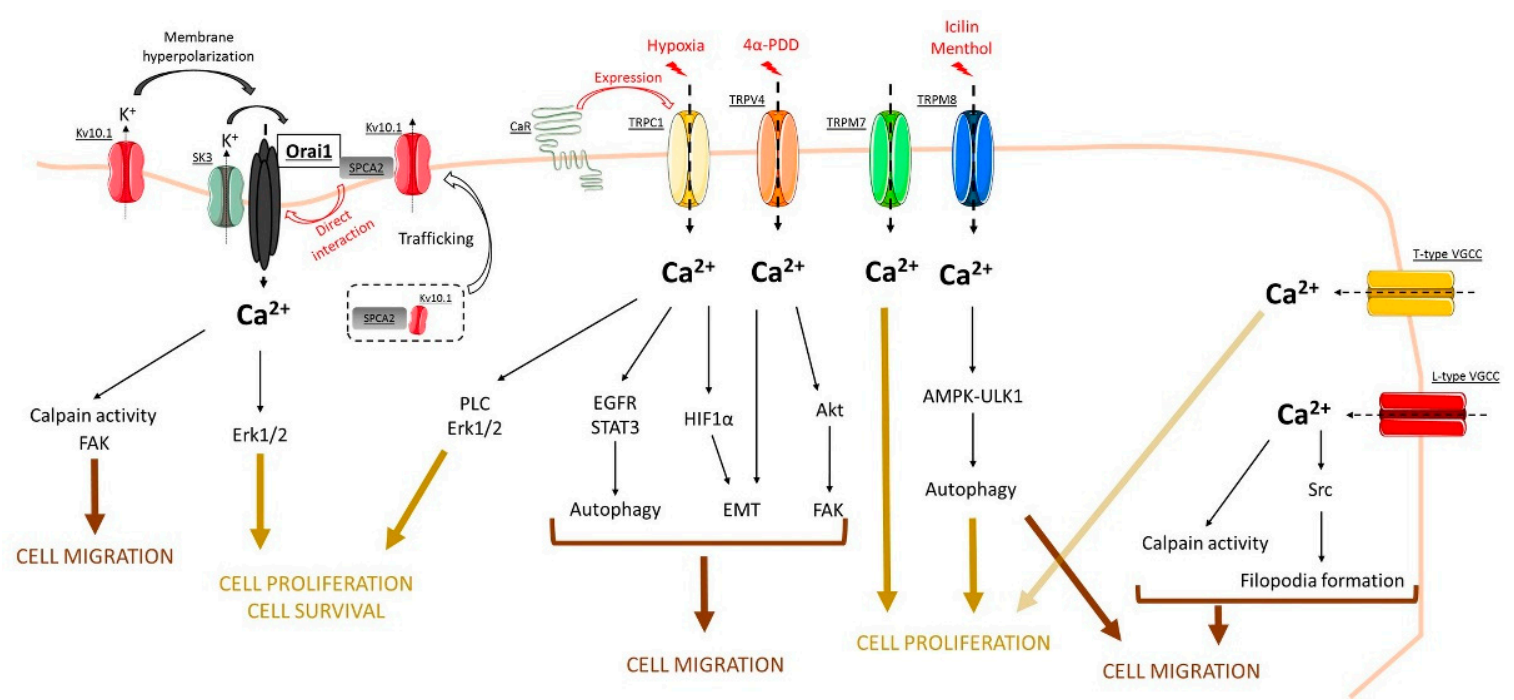

Figure 1. Concluding model that summarizes the role of store-independent calcium entry (SICE) through Orai, TRP, and voltage-gated calcium channels in the regulation of breast cancer processes. See, in the text, the role of each channel in cell processes such as cell proliferation, cell survival, as well as cell migration.

Author Contributions: Writing-original draft preparation, M.C., L.R.-D. and H.O.-A.; writing —review and editing, M.C., L.R.-D. and H.O.-A.; visualization, M.C., L.R.-D. and H.O.-A. All authors have read and agreed to the published version of the manuscript.

Funding: M.C. is grateful for the funding from the "Ministère de l'Enseignement Supérieur et de la Recherche", the "Université de Picardie Jules Verne", and the "Cancéropôle Nord-Ouest". This work was supported by the "Université de Picardie Jules Verne", the "Région Hauts-de-France", the "Ligue contre le cancer", and the "Cancéropôle Nord-Ouest".

Conflicts of Interest: The authors declare no conflict of interest.

\section{Abbreviations}

AA

AMPK-ULK1

BC

$\mathrm{Ca}^{2+}$

$\mathrm{CaR}$

C-ter

EGFR

EMT

$\mathrm{ER}^{+}$

$\mathrm{ER}^{-}$

Erk1/2

FAK

HIF1 $\alpha$

Kv10.1

LTC4

miRNA

$\mathrm{N}$-ter

PLC

SICE

SK3
Arachidonic acid;

AMP-activated protein kinase-Unc-51 like autophagy activating kinase 1;

Breast cancer;

Calcium;

Calcium-sensing receptor;

carboxyl terminus;

Epidermal growth factor;

Epithelial-mesenchymal transition;

Estrogen receptor positive;

Estrogen receptor negative;

Extracellular signal-regulated kinases 1 and 2;

Focal adhesion kinase;

Hypoxia-inducible factor $1 \alpha$;

Voltage-gated potassium channel;

AA metabolite leukotriene C4 (LTC4);

Micro-ribonucleic acid;

Amino terminus;

Phospholipase C;

Store-independent calcium entry;

Small conductance calcium-activated potassium channel; 


$\begin{array}{ll}\text { SOC } & \text { Store-operated channels; } \\ \text { SOCE } & \text { Store-operated calcium entry; } \\ \text { SOX4 } & \text { SRY-Box transcription factor 4; } \\ \text { SPCA2 } & \text { Secretory pathway calcium-ATPase; } \\ \text { Src } & \text { Proto-oncogene tyrosine kinase Src; } \\ \text { STAT3 } & \text { Signal transducers and activators of transcription 3; } \\ \text { STIM } & \text { Stromal interaction molecule; } \\ \text { TRP } & \text { Transient receptor potential; } \\ \text { TRPC } & \text { Transient receptor potential canonical; } \\ \text { TRPM } & \text { Transient receptor potential melastatin; } \\ \text { TRPV } & \text { Transient receptor potential vanilloid; } \\ \text { VGCC } & \text { Voltage-gated calcium channel; } \\ 4 \alpha-P D D & 4-\alpha \text {-phorbol-12,13-didecanoate. }\end{array}$

\section{References}

1. Lang, F.; Stournaras, C. Ion channels in cancer: Future perspectives and clinical potential. Philos. Trans. R. Soc. London. Ser. B Biol. Sci. 2014, 369, 20130108. [CrossRef]

2. Prevarskaya, N.; Skrryma, R.; Shuuba, Y. Ion Channels in Cancer: Are Cancer Hallmarks Oncochannelopathies? Physiol. Rev. 2018, 98, 559-621. [CrossRef]

3. Tajada, S.; Villalobos, C. Calcium Permeable Channels in Cancer Hallmarks. Front. Pharmacol. 2020, 11, 968. [CrossRef] [PubMed]

4. Petersen, O.H.; Michalak, M.; Verkhratsky, A. Calcium signalling: Past, present and future. Cell Calcium 2005, 38, 161-169. [CrossRef]

5. Berridge, M.J.; Bootman, M.D.; Lipp, P. Calcium-A life and death signal. Nature 1998, 395, 645-648. [CrossRef]

6. So, C.L.; Saunus, J.M.; Roberts-Thomson, S.J.; Monteith, G.R. Calcium signalling and breast cancer. Semin. Cell Dev. Biol. 2019, 94, 74-83. [CrossRef]

7. Hogan, P.G.; Rao, A. Store-operated calcium entry: Mechanisms and modulation. Biochem. Biophys. Res. Commun. 2015, 460, 40-49. [CrossRef]

8. Jardin, I.; Lopez, J.J.; Salido, G.M.; Rosado, J.A. Store-Operated Ca(2+) Entry in Breast Cancer Cells: Remodeling and Functional Role. Int. J. Mol. Sci. 2018, 19, 4053. [CrossRef]

9. Zhang, X.; Gueguinou, M.; Trebak, M. Store-Independent Orai Channels Regulated by STIM. In Calcium Entry Channels in Non-Excitable Cells; Kozak, J.A., Putney, J.W., Jr., Eds.; CRC Press: Boca Raton, FL, USA, 2018; pp. 197-214.

10. Feng, M.; Grice, D.M.; Faddy, H.M.; Nguyen, N.; Leitch, S.; Wang, Y.; Muend, S.; Kenny, P.A.; Sukumar, S.; Roberts-Thomson, S.J.; et al. Store-independent activation of Orai1 by SPCA2 in mammary tumors. Cell 2010, 143, 84-98. [CrossRef] [PubMed]

11. Phan, N.N.; Wang, C.Y.; Chen, C.F.; Sun, Z.; Lai, M.D.; Lin, Y.C. Voltage-gated calcium channels: Novel targets for cancer therapy. Oncol. Lett. 2017, 14, 2059-2074. [CrossRef] [PubMed]

12. Deliot, N. Constantin, B. Plasma membrane calcium channels in cancer: Alterations and consequences for cell proliferation and migration. Biochim. Biophys. Acta 2015, 1848, 2512-2522. [CrossRef]

13. Mignen, O.; Constantin, B.; Potier-Cartereau, M.; Penna, A.; Gautier, M.; Gueguinou, M.; Renaudineau, Y.; Shoji, K.F.; Felix, R.; Bayet, E.; et al. Constitutive calcium entry and cancer: Updated views and insights. Eur. Biophys. J. EBJ 2017, 46, 395-413. [CrossRef]

14. Chen, Y.F.; Lin, P.C.; Yeh, Y.M.; Chen, L.H.; Shen, M.R. Store-Operated Ca(2+) Entry in Tumor Progression: From Molecular Mechanisms to Clinical Implications. Cancers 2019, 11, 899. [CrossRef] [PubMed]

15. Chalmers, S.B.; Monteith, G.R. ORAI channels and cancer. Cell Calcium 2018, 74, 160-167. [CrossRef]

16. Faouzi, M.; Hague, F.; Potier, M.; Ahidouch, A.; Sevestre, H.; Ouadid-Ahidouch, H. Down-regulation of Orai3 arrests cell-cycle progression and induces apoptosis in breast cancer cells but not in normal breast epithelial cells. J. Cell. Physiol. 2011, 226, 542-551. [CrossRef]

17. Faouzi, M.; Kischel, P.; Hague, F.; Ahidouch, A.; Benzerdjeb, N.; Sevestre, H.; Penner, R.; Ouadid-Ahidouch, H. ORAI3 silencing alters cell proliferation and cell cycle progression via c-myc pathway in breast cancer cells. Biochim. Biophys. Acta 2013, 1833, 752-760. [CrossRef]

18. Hasna, J.; Hague, F.; Rodat-Despoix, L.; Geerts, D.; Leroy, C.; Tulasne, D.; Ouadid-Ahidouch, H.; Kischel, P. Orai3 calcium channel and resistance to chemotherapy in breast cancer cells: The p53 connection. Cell Death Differ. 2018, 25, 693-707. [CrossRef] [PubMed]

19. Azimi, I.; Milevskiy, M.J.G.; Chalmers, S.B.; Yapa, K.; Robitaille, M.; Henry, C.; Baillie, G.J.; Thompson, E.W.; Roberts-Thomson, S.J.; Monteith, G.R. ORAI1 and ORAI3 in Breast Cancer Molecular Subtypes and the Identification of ORAI3 as a Hypoxia Sensitive Gene and a Regulator of Hypoxia Responses. Cancers 2019, 11, 208. [CrossRef] [PubMed]

20. Vashisht, A.; Tanwar, J.; Motiani, R.K. Regulation of proto-oncogene Orai3 by miR18a/b and miR34a. Cell Calcium 2018, 75, 101-111. [CrossRef] 
21. McAndrew, D.; Grice, D.M.; Peters, A.A.; Davis, F.M.; Stewart, T.; Rice, M.; Smart, C.E.; Brown, M.A.; Kenny, P.A.; RobertsThomson, S.J.; et al. ORAI1-mediated calcium influx in lactation and in breast cancer. Mol. Cancer Ther. 2011, 10, 448-460. [CrossRef] [PubMed]

22. Yang, S.; Zhang, J.J.; Huang, X.Y. Orai1 and STIM1 are critical for breast tumor cell migration and metastasis. Cancer Cell 2009, 15, 124-134. [CrossRef]

23. Jardin, I.; Diez-Bello, R.; Lopez, J.J.; Redondo, P.C.; Salido, G.M.; Smani, T.; Rosado, J.A. TRPC6 Channels Are Required for Proliferation, Migration and Invasion of Breast Cancer Cell Lines by Modulation of Orai1 and Orai3 Surface Exposure. Cancers 2018, 10, 331. [CrossRef]

24. Motiani, R.K.; Abdullaev, I.F.; Trebak, M. A novel native store-operated calcium channel encoded by Orai3: Selective requirement of Orai3 versus Orai1 in estrogen receptor-positive versus estrogen receptor-negative breast cancer cells. J. Biol. Chem. 2010, 285, 19173-19183. [CrossRef] [PubMed]

25. Cross, B.M.; Hack, A.; Reinhardt, T.A.; Rao, R. SPCA2 regulates Orai1 trafficking and store independent Ca2+ entry in a model of lactation. PLoS ONE 2013, 8, e67348. [CrossRef]

26. Peretti, M.; Badaoui, M.; Girault, A.; van Gulick, L.; Mabille, M.P.; Tebbakha, R.; Sevestre, H.; Morjani, H.; Ouadid-Ahidouch, H. Original association of ion transporters mediates the ECM-induced breast cancer cell survival: Kv10.1-Orai1-SPCA2 partnership. Sci. Rep. 2019, 9, 1175. [CrossRef] [PubMed]

27. Girault, A.; Peretti, M.; Badaoui, M.; Hemon, A.; Morjani, H.; Ouadid-Ahidouch, H. The N and C-termini of SPCA2 regulate differently Kv10.1 function: Role in the collagen 1-induced breast cancer cell survival. Am. J. Cancer Res. 2021, 11, $251-263$.

28. Badaoui, M.; Mimsy-Julienne, C.; Saby, C.; van Gulick, L.; Peretti, M.; Jeannesson, P.; Morjani, H.; Ouadid-Ahidouch, H. Collagen type 1 promotes survival of human breast cancer cells by overexpressing Kv10.1 potassium and Orai1 calcium channels through DDR1-dependent pathway. Oncotarget 2018, 9, 24653-24671. [CrossRef] [PubMed]

29. Schwab, A.; Hanley, P.; Fabian, A.; Stock, C. Potassium channels keep mobile cells on the go. Physiology 2008, 23, 212-220. [CrossRef]

30. Hammadi, M.; Chopin, V.; Matifat, F.; Dhennin-Duthille, I.; Chasseraud, M.; Sevestre, H.; Ouadid-Ahidouch, H. Human ether a-gogo $\mathrm{K}(+)$ channel 1 (hEag1) regulates MDA-MB-231 breast cancer cell migration through Orai1-dependent calcium entry. J. Cell. Physiol. 2012, 227, 3837-3846. [CrossRef]

31. Chantome, A.; Potier-Cartereau, M.; Clarysse, L.; Fromont, G.; Marionneau-Lambot, S.; Gueguinou, M.; Pages, J.C.; Collin, C.; Oullier, T.; Girault, A.; et al. Pivotal role of the lipid Raft SK3-Orai1 complex in human cancer cell migration and bone metastases. Cancer Res. 2013, 73, 4852-4861. [CrossRef]

32. Gueguinou, M.; Crottes, D.; Chantome, A.; Rapetti-Mauss, R.; Potier-Cartereau, M.; Clarysse, L.; Girault, A.; Fourbon, Y.; Jezequel, P.; Guerin-Charbonnel, C.; et al. The SigmaR1 chaperone drives breast and colorectal cancer cell migration by tuning SK3-dependent $\mathrm{Ca}(2+)$ homeostasis. Oncogene 2017, 36, 3640-3647. [CrossRef]

33. Chodon, D.; Guilbert, A.; Dhennin-Duthille, I.; Gautier, M.; Telliez, M.S.; Sevestre, H.; Ouadid-Ahidouch, H. Estrogen regulation of TRPM8 expression in breast cancer cells. BMC Cancer 2010, 10, 212. [CrossRef] [PubMed]

34. Dhennin-Duthille, I.; Gautier, M.; Faouzi, M.; Guilbert, A.; Brevet, M.; Vaudry, D.; Ahidouch, A.; Sevestre, H.; Ouadid-Ahidouch, H. High expression of transient receptor potential channels in human breast cancer epithelial cells and tissues: Correlation with pathological parameters. Cell. Physiol. Biochem. Int. J. Exp. Cell. Physiol. Biochem. Pharmacol. 2011, $28,813-822$. [CrossRef] [PubMed]

35. El Hiani, Y.; Ahidouch, A.; Roudbaraki, M.; Guenin, S.; Brule, G.; Ouadid-Ahidouch, H. Calcium-sensing receptor stimulation induces nonselective cation channel activation in breast cancer cells. J. Membr. Biol. 2006, 211, 127-137. [CrossRef] [PubMed]

36. Guilbert, A.; Dhennin-Duthille, I.; Hiani, Y.E.; Haren, N.; Khorsi, H.; Sevestre, H.; Ahidouch, A.; Ouadid-Ahidouch, H. Expression of TRPC6 channels in human epithelial breast cancer cells. BMC Cancer 2008, 8, 125. [CrossRef]

37. Guilbert, A.; Gautier, M.; Dhennin-Duthille, I.; Haren, N.; Sevestre, H.; Ouadid-Ahidouch, H. Evidence that TRPM7 is required for breast cancer cell proliferation. Am. J. Physiol. Cell Physiol. 2009, 297, C493-C502. [CrossRef]

38. Ouadid-Ahidouch, H.; Dhennin-Duthille, I.; Gautier, M.; Sevestre, H.; Ahidouch, A. TRP calcium channel and breast cancer: Expression, role and correlation with clinical parameters. Bull. Cancer 2012, 99, 655-664. [CrossRef]

39. Aydar, E.; Yeo, S.; Djamgoz, M.; Palmer, C. Abnormal expression, localization and interaction of canonical transient receptor potential ion channels in human breast cancer cell lines and tissues: A potential target for breast cancer diagnosis and therapy. Cancer Cell Int. 2009, 9, 23. [CrossRef]

40. Lee, W.H.; Choong, L.Y.; Jin, T.H.; Mon, N.N.; Chong, S.; Liew, C.S.; Putti, T.; Lu, S.Y.; Harteneck, C.; Lim, Y.P. TRPV4 plays a role in breast cancer cell migration via $\mathrm{Ca}(2+)$-dependent activation of AKT and downregulation of E-cadherin cell cortex protein. Oncogenesis 2017, 6, e338. [CrossRef]

41. Guilbert, A.; Gautier, M.; Dhennin-Duthille, I.; Rybarczyk, P.; Sahni, J.; Sevestre, H.; Scharenberg, A.M.; Ouadid-Ahidouch, H. Transient receptor potential melastatin 7 is involved in oestrogen receptor-negative metastatic breast cancer cells migration through its kinase domain. Eur. J. Cancer 2013, 49, 3694-3707. [CrossRef]

42. Meng, X.; Cai, C.; Wu, J.; Cai, S.; Ye, C.; Chen, H.; Yang, Z.; Zeng, H.; Shen, Q.; Zou, F. TRPM7 mediates breast cancer cell migration and invasion through the MAPK pathway. Cancer Lett. 2013, 333, 96-102. [CrossRef] 
43. El Hiani, Y.; Ahidouch, A.; Lehen'kyi, V.; Hague, F.; Gouilleux, F.; Mentaverri, R.; Kamel, S.; Lassoued, K.; Brule, G.; OuadidAhidouch, H. Extracellular signal-regulated kinases 1 and 2 and TRPC1 channels are required for calcium-sensing receptorstimulated MCF-7 breast cancer cell proliferation. Cell. Physiol. Biochem. Int. J. Exp. Cell. Physiol. Biochem. Pharmacol. 2009, 23, 335-346. [CrossRef]

44. Brown, E.M.; Gamba, G.; Riccardi, D.; Lombardi, M.; Butters, R.; Kifor, O.; Sun, A.; Hediger, M.A.; Lytton, J.; Hebert, S.C. Cloning and characterization of an extracellular $\mathrm{Ca}(2+)$-sensing receptor from bovine parathyroid. Nature 1993, 366, 575-580. [CrossRef]

45. Sanders, J.L.; Chattopadhyay, N.; Kifor, O.; Yamaguchi, T.; Butters, R.R.; Brown, E.M. Extracellular calcium-sensing receptor expression and its potential role in regulating parathyroid hormone-related peptide secretion in human breast cancer cell lines. Endocrinology 2000, 141, 4357-4364. [CrossRef] [PubMed]

46. Azimi, I.; Milevskiy, M.J.G.; Kaemmerer, E.; Turner, D.; Yapa, K.; Brown, M.A.; Thompson, E.W.; Roberts-Thomson, S.J.; Monteith, G.R. TRPC1 is a differential regulator of hypoxia-mediated events and Akt signalling in PTEN-deficient breast cancer cells. J. Cell Sci. 2017, 130, 2292-2305. [CrossRef]

47. Azimi, I.; Robitaille, M.; Armitage, K.; So, C.L.; Milevskiy, M.J.G.; Northwood, K.; Lim, H.F.; Thompson, E.W.; Roberts-Thomson, S.J.; Monteith, G.R. Activation of the Ion Channel TRPV4 Induces Epithelial to Mesenchymal Transition in Breast Cancer Cells. Int. J. Mol. Sci. 2020, 21, 9417. [CrossRef]

48. Middelbeek, J.; Kuipers, A.J.; Henneman, L.; Visser, D.; Eidhof, I.; van Horssen, R.; Wieringa, B.; Canisius, S.V.; Zwart, W.; Wessels, L.F.; et al. TRPM7 is required for breast tumor cell metastasis. Cancer Res. 2012, 72, 4250-4261. [CrossRef] [PubMed]

49. Kuipers, A.J.; Middelbeek, J.; Vrenken, K.; Perez-Gonzalez, C.; Poelmans, G.; Klarenbeek, J.; Jalink, K.; Trepat, X.; van Leeuwen, F.N. TRPM7 controls mesenchymal features of breast cancer cells by tensional regulation of SOX4. Biochim. Biophys. Acta Mol. Basis Dis. 2018, 1864, 2409-2419. [CrossRef] [PubMed]

50. Huang, Y.; Li, S.; Jia, Z.; Zhao, W.; Zhou, C.; Zhang, R.; Ali, D.W.; Michalak, M.; Chen, X.Z.; Tang, J. Transient Receptor Potential Melastatin 8 (TRPM8) Channel Regulates Proliferation and Migration of Breast Cancer Cells by Activating the AMPK-ULK1 Pathway to Enhance Basal Autophagy. Front. Oncol. 2020, 10, 573127. [CrossRef]

51. Roger, S.; Besson, P.; le Guennec, J.Y. Involvement of a novel fast inward sodium current in the invasion capacity of a breast cancer cell line. Biochim. Biophys. Acta 2003, 1616, 107-111. [CrossRef] [PubMed]

52. Wonderlin, W.F.; Woodfork, K.A.; Strobl, J.S. Changes in membrane potential during the progression of MCF-7 human mammary tumor cells through the cell cycle. J. Cell. Physiol. 1995, 165, 177-185. [CrossRef] [PubMed]

53. Ouadid-Ahidouch, H.; le Bourhis, X.; Roudbaraki, M.; Toillon, R.A.; Delcourt, P.; Prevarskaya, N. Changes in the K+ currentdensity of MCF-7 cells during progression through the cell cycle: Possible involvement of a h-ether.a-gogo K+ channel. Recept. Channels 2001, 7, 345-356.

54. Barcelo, C.; Siso, P.; Maiques, O.; de la Rosa, I.; Marti, R.M.; Macia, A. T-Type Calcium Channels: A Potential Novel Target in Melanoma. Cancers 2020, 12, 391. [CrossRef]

55. Ohkubo, T.; Yamazaki, J. T-type voltage-activated calcium channel Cav3.1, but not Cav3.2, is involved in the inhibition of proliferation and apoptosis in MCF-7 human breast cancer cells. Int. J. Oncol. 2012, 41, 267-275. [CrossRef]

56. Wang, C.Y.; Lai, M.D.; Phan, N.N.; Sun, Z.; Lin, Y.C. Meta-Analysis of Public Microarray Datasets Reveals Voltage-Gated Calcium Gene Signatures in Clinical Cancer Patients. PLoS ONE 2015, 10, e0125766. [CrossRef] [PubMed]

57. Marques, R.; Peres, C.G.; Vaz, C.V.; Gomes, I.M.; Figueira, M.I.; Cairrao, E.; Verde, I.; Maia, C.J.; Socorro, S. 5alphaDihydrotestosterone regulates the expression of L-type calcium channels and calcium-binding protein regucalcin in human breast cancer cells with suppression of cell growth. Med Oncol. 2015, 32, 228. [CrossRef] [PubMed]

58. Squecco, R.; Tani, A.; Zecchi-Orlandini, S.; Formigli, L.; Francini, F. Melatonin affects voltage-dependent calcium and potassium currents in MCF-7 cell line cultured either in growth or differentiation medium. Eur. J. Pharmacol. 2015, 758, 40-52. [CrossRef]

59. Kanwar, N.; Carmine-Simmen, K.; Nair, R.; Wang, C.; Moghadas-Jafari, S.; Blaser, H.; Tran-Thanh, D.; Wang, D.; Wang, P.; Wang, J.; et al. Amplification of a calcium channel subunit CACNG4 increases breast cancer metastasis. EBioMedicine 2020, 52, 102646. [CrossRef]

60. Jacquemet, G.; Baghirov, H.; Georgiadou, M.; Sihto, H.; Peuhu, E.; Cettour-Janet, P.; He, T.; Perala, M.; Kronqvist, P.; Joensuu, H.; et al. L-type calcium channels regulate filopodia stability and cancer cell invasion downstream of integrin signalling. Nat. Commun. 2016, 7, 13297. [CrossRef]

61. Bertolesi, G.E.; Shi, C.; Elbaum, L.; Jollimore, C.; Rozenberg, G.; Barnes, S.; Kelly, M.E. The Ca(2+) channel antagonists mibefradil and pimozide inhibit cell growth via different cytotoxic mechanisms. Mol. Pharmacol. 2002, 62, 210-219. [CrossRef]

62. Taylor, J.T.; Huang, L.; Pottle, J.E.; Liu, K.; Yang, Y.; Zeng, X.; Keyser, B.M.; Agrawal, K.C.; Hansen, J.B.; Li, M. Selective blockade of T-type Ca2+ channels suppresses human breast cancer cell proliferation. Cancer Lett. 2008, 267, 116-124. [CrossRef] [PubMed] 